\title{
EBM notebook
}

\section{Clinical skills textbooks fail evidence-based examination}

\section{BACKGROUND}

Despite advances in "technological" medicine, the history and physical examination still provide the correct final diagnosis in the majority of $\operatorname{cases}^{1}{ }^{2}$ and remain the cornerstone of clinical medicine. ${ }^{3}$ Medical students spend a great deal of time learning these techniques. Students continue to be taught the long case "complete history and physical," despite its inefficiency and errors. Bordage ${ }^{4}$ claims "you see what you are looking for," and gathering further data fails to increase diagnostic accuracy. Educational research suggests diagnostic accuracy depends on both mastery of knowledge and sound problem solving strategies. ${ }^{5}$ Students can learn to problem solve more expertly by using schemes that assist storage and retrieval of clinical knowledge, rather than rote memorisation of lists and "dispersed" knowledge. ${ }^{5}{ }^{6}$

Diagnosis involves gathering clinical information and then refining the probability of a particular diagnosis after acquiring each piece of evidence. The elements of history and examination can be considered as individual "diagnostic" tests; thus Bayes' theorem informs this decision making approach to diagnosis. ${ }^{3}$

Even in familiar settings, clinicians, and students to a greater extent, make erroneous estimates of disease probability given the clinical features of the presentation. ${ }^{8}$ 9 Clinical textbooks seldom provide the frequency of clinical manifestations of particular diseases, even where good evidence exists. ${ }^{910}$ Such evidence can help medical teaching focus on diagnostic manoeuvres with proven utility, discarding time honoured but diagnostically unhelpful manoeuvres. ${ }^{11}$

While teaching clinical students we noted their difficulty in learning clinical methods and felt that many texts of clinical skills used by students do not assist them, and indeed often add to their confusion. We attempted to determine whether this impression was correct by examining basic clinical skills textbooks.

To do this, we obtained recent editions of clinical skills textbooks recommended by official booklists to students at Australian and Hong Kong medical schools. Pairs of reviewers - 2 academic staff, and 2 students in the first clinical year of the Queensland course-independently examined each textbook to determine the amount and quality of

- discussion about the diagnostic process and clinical decision making;

- general interpretation of the accuracy and reliability of symptoms and signs discussed in a section or chapter of its own;

- provision of accuracy and reliability of specific history and examination findings;

- information on disease frequency, or relative frequency of a sign in a particular disease.

We found no suitable rating scales so assigned a score of 0 3 to each question. The reviewers met in pairs to discuss their interpretations and develop consensus ratings. Other comments noted by each reviewer were analysed qualitatively for recurring themes.

We obtained 10 textbooks on "physical diagnosis." 6 originated from the $\mathrm{UK}^{12-17} \mathrm{l}$ from the US, ${ }^{18}$ and 3 from Australia. ${ }^{19-21}$ The most common text was Talley and O'Connor ( 10 of the 12 medical schools).

The reviewers' assessments are shown in the table. Talley and $\mathrm{O}^{\prime}$ Connor ${ }^{21}$ would have received a higher score for coverage of reliability of specific symptoms and signs had they discussed evidence in the body of the text, rather than embedding annotations within the reference lists.

Many texts describe only the traditional approach in which the student is expected to take a complete history in an unspecified time frame, then wait for inspiration-for example, "when the facts are complete, attempt to find a diagnosis." 12 The word "should" was noted to occur frequently-for example, "a rectal examination should be performed on every patient."

While some books listed questions or examinations as a basic set for each system, none gave the reasons for selecting these particular items (either individually, or as a group). The authors thus provided no guide for students to distinguish clinical features with high likelihood ratios.

Most books described or illustrated the severe and classic cases, while omitting conditions commonly seen in primary care-for example, cystitis was often omitted from urology chapters. Content of texts was weighted towards clinical conditions rather than clinical presentations-that is, they discussed the manifestations of disease $\mathrm{x}$, rather than how a symptom complex can be analysed to make the diagnosis. Several texts included sections on radiology and pathology, but we felt they only partially covered these topics, straying beyond the clinical skills focus, yet without properly integrating the results of tests into the process of diagnosis.

Learning clinical skills is central to the medical course, but we found the textbooks recommended for students poorly organised for learning. They failed to integrate lessons from medical education research and available evidence about the effectiveness of aspects of the physical examination. From the texts reviewed, only 3 would earn a bare pass on the rating criteria assessed..$^{18} 2021$

Initial rating scores varied little among reviewers, although the students were less critical of identified deficiencies. The summary scores do not communicate the details of whether or not specific issues were covered. However, our results are consistent with other studies, which find that textbooks consistently fail to report the precision and accuracy of clinical signs. ${ }^{22}$ Some evidence-based physical diagnosis texts are currently available-McGee is an example, ${ }^{1}$ although its limited scope of medical conditions covered and instructions on physical examination make it unsuitable as a stand-alone introductory text for students. ${ }^{23}$

Students need assistance to progress from the initial all inclusive approach to the abbreviated approach used by experienced clinicians. Time efficient, selective clinical examination, without cutting corners that sacrifice 
132

diagnostic accuracy, is a complex skill that could be taught more directly using the principles of clinical reasoning and problem solving. Texts on clinical reasoning are available, with Barrows and Pickell ${ }^{24}$ and Glass ${ }^{25}$ being examples that would suit medical student needs.

It may be unrealistic to expect a single book to fulfil all of these expectations, but they could provide an approach and guide students toward further learning resources. Such discussions need not be lengthy, as shown by Fraser. ${ }^{26}$

Introductory texts that teach the mechanics of history taking and physical examination currently fail to include adequate guidance on the process of clinical decision making under uncertainty, using the best available evidence.

DAVID B KING, FRACGP, MBBS, MPH Centre for General Practice, School of Medicine, University of Queensland Brisbane, Queensland, Australia

JAMES A DICKINSON, MB FRACGP, PHD Dept of Family Medicine University of Calgary Calgary, Alberta, Canada

MARIA-RENEE BOULTON, MBBS CHRIS TOUMPAS, MBBS Queensland Health Department Brisbane, Queensland, Australia

1 McGee S. Evidence-based physical diagnosis. Philadelphia: W B Saunders Company, 2001.

2 Sackett DL, Rennie D. The science of the art of the clinical examination [editorial]. JAMA 1992;267:2650-52

3 Hatala R, Smieja M, Kane SL, et al. An evidenced-based approach to the clinical examination. J Gen Intern Med 1997;12:182-87.

4 Bordage G. Why did I miss the diagnosis? Some cognitive explanations and educational implications. Acad Med 1999:74(10 Suppl):S138-43.

5 Mandin $\mathrm{H}$, Jones A, Woloschuk W, et al. Helping students learn to think like experts when solving clinical problems. Acad Med 1997;72:173-9.

6 Elstein AS, Schwarz A. Clinical problem solving and diagnostic decision making: selective review of the cognitive literature. BMJ 2002;324:729-32.

7 Schmidt HG, Norman GR, Boshuizen HP. A cognitive perspective on medical expertise: theory and implication. Acad Med 1990;65:61 1-21.
8 Wallsten TS. Physician and medical student bias in evaluating diagnostic information. Med Decis Making 1981;1:145-64.

9 Richardson WS, Wilson MC. Textbook descriptions of disease-where's the beef? [EBM note]. Evidence-Based Medicine 2002;7:100-1.

10 Sackett DL. The rational clinical examination. A primer on the precision and accuracy of the clinical examination. JAMA 1992;267:2638-44.

11 Anderson RC, Fagan MJ, Sebastian J. Teaching students the art and science of physical diagnosis. Am J Med 2001;110:419-23.

12 Ogilvie C, Evans CC. Chamberlain's symptoms and signs in clinical medicine: an introduction to medical diagnosis. 12th ed. Oxford: Butterworth Heinemann, 1997.

13 Munro JF, Campbell IW, editors. Macleod's clinical examination. 10th ed. Edinburgh: Churchill Livingstone, 2000

14 Toghill PJ, Gray D, editors. An introduction to the symptoms and signs of clinical medicine. London: Arnold, 2001.

15 Browse NL. An introduction to the symptoms and signs of surgical disease. 3rd ed. London: Arnold, 1997.

16 Swash M, editor. Hutchison's clinical methods. 21 st ed. Edinburgh: WB Saunders, 2002.

17 Lumley JS. Hamilton Bailey's physical signs: demonstrations of physical signs in clinical surgery. 18th ed. Oxford: Butterworth-Heinemann, 1997.

18 Bickley LS, Hoekelman RA. Bates' guide to physical examination and history taking. 7th ed. Philadelphia: Lippincott-Raven, 1999.

19 Davis AE, Bolin TD, Ham JM. Symptom analysis and physical diagnosis. Sydney: Pergamon Press, 1985.

20 Larkins R, Smallwood R. Clinical skills: the medical interview, physical examination and assessment of the patients problem. Carlton: Melbourne University Press, 1993

21 Talley N, O'Connor S. Clinical examination: a systematic guide to physical diagnosis. 4th ed. Sydney: McLennan \& Petty, 2001

22 McAlister FA, Straus SE, Sackett DL. Why we need large, simple studies of the clinical examination: the problem and a proposed solution. Lancet 1999:354:1721-4.

23 Simel D. Resource Corner: Evidence-based physical diagnosis. EvidenceBased Medicine 2001;6:167

24 Barrows HS, Pickell GC. Developing clinical problem-solving skills: a guide to more effective diagnosis and treatment. New York: W W Norton, 1991

25 Glass R D. Diagnosis: a brief introduction. Melbourne: Oxford University Press, 1996.

26 Fraser R. Clinical method: a general practice approach. 3rd ed. Oxford: Butterworth Heinemann, 1999.

Rating of clinical skills texts for evidence-based approach

\begin{tabular}{|c|c|c|c|c|c|c|}
\hline Textbook & $\begin{array}{l}\text { Discussion about } \\
\text { diagnostic } \\
\text { process }\end{array}$ & $\begin{array}{l}\text { General discussion } \\
\text { of accuracy and } \\
\text { reliability }\end{array}$ & $\begin{array}{l}\text { Accuracy of specific } \\
\text { signs or symptoms } \\
\text { provided }\end{array}$ & $\begin{array}{l}\text { References } \\
\text { provided }\end{array}$ & $\begin{array}{l}\text { Relative frequency } \\
\text { of disease or } \\
\text { clinical finding }\end{array}$ & Comments \\
\hline Bates & 2 & 1 & 0 & 1 & 0 & $\begin{array}{l}\text { Discusses evidence-based medicine and } \\
\text { the diagnostic process }\end{array}$ \\
\hline Davies & $0^{*}$ & 0 & 0 & 0 & 0 & A brief primer rather than a textbook \\
\hline $\begin{array}{l}\text { Ogilvie \& } \\
\text { Evans }\end{array}$ & $0^{*}$ & 0 & 0 & 0 & $0 / 1$ & Good diagrams, tables and photographs \\
\hline $\begin{array}{l}\text { Larkins \& } \\
\text { Smallwood }\end{array}$ & 2 & 0 & 0 & 1 & $0 / 1$ & Only 1 reference cited in entire book \\
\hline $\begin{array}{l}\text { Talley \& } \\
\text { O'Connor }\end{array}$ & 1 & 0 & 1 & 2 & 2 & \multirow{5}{*}{$\begin{array}{l}\text { Section correlating symptoms and signs } \\
\text { with particular diseases } \\
\text { Useful chapter conclusions on common } \\
\text { pitfalls ( } v \text { brief) } \\
\text { Mention of prevalence of conditions and } \\
\text { survival rates } \\
\text { Tables on common and less common } \\
\text { causes for some presentations }\end{array}$} \\
\hline $\begin{array}{l}\text { Munro \& } \\
\text { Campbell }\end{array}$ & 1 & 0 & 0 & 1 & 2 & \\
\hline Lumley & $0^{*}$ & 0 & 0 & 0 & 1 & \\
\hline Gray \& Toghill & 1 & 1 & 0 & 0 & 2 & \\
\hline $\begin{array}{l}\text { Swash \& } \\
\text { Hutchinson }\end{array}$ & 1 & 1 & 1 & 0 & 0 & \\
\hline Browse & 0 & 0 & 0 & 0 & $0 / 1$ & $\begin{array}{l}\text { Traditional surgical text disease-based } \\
\text { approach }\end{array}$ \\
\hline
\end{tabular}

*Cells in which students' rating prior to consensus differed from academics. Their initial rating for each of these 3 texts was " 1 "

Rating Scale

$0-$ no mention of concept

1 -concept explained briefly, no examples given

2 -concept explained and some examples given

3-concept consistently explained and applied throughout book. 